\title{
Teaching Management and Its Contribution Student Satisfaction in Private Higher Institutions of Learning
}

\author{
Sabarudin Zakaria and Wan Fadzilah Wan Yusoff
}

\begin{abstract}
As students in the private higher institutions of learning (HILs) become more discerning about the quality learning environment, especially in teaching, the HILs are striving to create a learning environment that can produce graduates of top quality. Apart from the teaching process itself, the goal of teaching is to improve students' learning by maximizing opportunities for learning. However, in many cases, the lecturers and the systems themselves fail to transfer knowledge to students effectively despite the presence of good facilities and infrastructure. This paper attempts to identify students' views on the importance of having a good teaching management and the satisfaction level they experience with the current situation in their university. A set of questionnaires was distributed to students in private higher learning institutions who enrolled in an undergraduate business-related program. Respondents were chosen from the first year to the final year students. The main outcome of this study is to identify what good education means in the context of having good infrastructure, team of good and competence educators, the syllabus, resources and the teaching process.
\end{abstract}

Index Terms-Quality, learning, environment, teaching, private higher learning, Malaysia

\section{INTRODUCTION}

The Malaysian education scene since achieving its independence in 1957 has been growing in leaps and bounds, especially with the establishment of many universities and colleges comprising of both public and private. This phenomenon has truly fulfilled the country's aspiration to form the base for future quality human capital equipped with relevant knowledge. The establishment of the Ministry of Higher education (MOHE) in 2004, as initiated by the government is geared towards making Malaysia as a center of educational excellence in producing skilled human workforce [1].

This can be seen with the expansion of the private higher education industry in Malaysia as shown in Table 1, start growing since early 90 s with the establishment of nearly 200

private higher education institutions that carry college status (Source: Ministry of Education, Department of Higher Education). Since then, the industry managed to attract investors to open more private higher education institution including foreign investors.

The aim of this study is to evaluate and analyze factors that

Manuscript received July 22, 2011; revised September 21, 2011

Sabarudin Zakaria is a lecturer with Multimedia University, Persiaran Multimedia, 63100 Cyberjaya, Selangor Darul Ehsan, Malaysia.(e-mail: sabarudin.zakaria@mmu.edu.my).

Wan Fadzilah Wan Yusuff is with Multimedia University, she was formerly the dean of Faculty of Management, Multimedia University (e-mail: wanfadzilah@mmu.edu.my). could possibly contribute to or deter the achievement of this Mission by focusing on the contributions of creating conducive teaching and learning environments through effective management. For the purpose of this study several indicators were identified and evaluated by several selected focus groups comprising students from the faculty of management.

The factors were further prioritized and refined to define what constitute a conducive teaching and learning environment. To bring meaning and logic to the results of the study, the points discussed were categorized into four segments: teaching, student, facilities and research. Consistent to one study in Bangladesh, these findings would be useful as a guide to professionals and policy-makers when formulating effective educational policy for this country.

TABLE 1: NUMBER OF PRIVATE HigheR EdUCATION INSTITUTION (PHEI) IN MALAYSIA FOR 2008 AND 2009.SOURCE: MiNISTRY OF HIGHER

\begin{tabular}{|c|c|c|}
\hline \multicolumn{3}{|l|}{ EDUCATION } \\
\hline Description & & \\
\hline & 2008 & 2009 \\
\hline PHEI - university status & 18 & 20 \\
\hline PHEI - college university status & 18 & 20 \\
\hline PHEI - foreign university branch & 4 & 5 \\
\hline PHEI - non university status & 430 & 393 \\
\hline TOTAL & 470 & 438 \\
\hline
\end{tabular}

\section{LITERATURE REVIEW}

The main thrust of any higher education institution is to inculcate quality through the delivery and continued enhancement of excellence in teaching and learning. This can be further enhanced by the combination of values of a liberal education with the professional qualifications relevant in a globalised economy [2]. True to today's education, the learning environment is the interaction and the application of many elements.

Basically the human factors, the educator and the infrastructure and the way they interact with the students often determine the outcome of any learning environment. This is consistent to Hansman concept of learning which espoused that learning is shaped by the context, culture, and tools in the learning situation', and not simply by something that happens, or by just being inside the head [3]. High quality education may be contributed from higher education properties but what is more significant is that the catalyst for improved performance coming from the interrelationship within the context of the organization [4].

This includes tangible factors such as classroom, accommodation and other facilities without forgetting the 
human factors; the lecturers and the services provided. The results of a survey distributed to students asking for their views on a complete student experience indicated that the factors include both academic and non-academic matters ranging from teaching style and teaching methods, library and computer provision right to broader issues such as the university environment, catering, accommodation and social life [5].

Higher education has never been more important in the globalised world. It lays the foundation for the economic, social and cultural being of any nation. Its major contribution is derived from the nation's ability to develop its citizens' intellectualism and enhancing their employability. On a more general view, higher education adds to the world's repository of knowledge and understanding by fostering culture and promoting the values that characterize higher education: respect for evidence; respect for individuals and their views and the search for truth [6]. One of the most important requirements to be met in order to attain quality higher education is in satisfying the students' expectations. Meeting the needs and expectations of the students, who are the principal beneficiaries of university education has become numero uno to most private HILs [7].

On the other hand, the staff (the teaching team, research support, administrative and service staff) had to be satisfied with their daily tasks and be considered an engine for the organization's forward movement. To achieve quality education, universities are pressured to change their methods of teaching and learning which encompass the appropriate assessment methods, continued renewal of the curriculum, constant updating and upgrading of professional knowledge and skills and improving the broader educational, administrative and resource environments [8]. [9] Suggests that a conducive learning environment include comfort in the lecture halls, individual study areas, libraries, instructional materials, support services, etc. Simply allowing learning to occur in a natural setting is no longer an option in the HILs. Therefore, availability of resources like funding, library and technical resource, administrative and faculty support within the HILs are important factors [10]. In fact, all elements within the environment should interact positively to enhance the learning process.

Other factors necessary in creating a conducive learning environment would include classroom management which extends beyond just maintaining strict and rigid control over the class and its contents - it implies an ability to establish a comfortable environment that allows everyone to learn and participate freely [11].Thus, the concept of conduciveness covers all aspects - not just the process itself but also the physical aspects which incorporate the functions of management. Rewards brought about by learners who have been transformed through higher education far exceed the 'value for money" criteria of the funding bodies and the community at large [12]. Creating a conducive educational environment is as important as what is taught and shared [13]. That is, it is not only the infrastructure, the technology, the educators, or the student itself but the management of all these factors. A learning environment also extends to state of the lecture halls, individual study areas, libraries, instructional materials, support services, etc. an enhancement of a learning process can only occur when a conducive learning environment is present [14]. According to [15] the learning environment should be productive rather than merely neutral. In his evaluation of adult learning environment, [16] concluded that higher education environment includes physical surroundings, psychological or emotional conditions, and social or cultural influences as they affect intellectual growth and development. Further, there is a general perception that many students are poorly prepared and have little concept of the basic requirements for study at higher education level, including study skills, motivation and independence [17].

\section{Methodology}

The main source of data used was obtained from a survey conducted during the $2^{\text {nd }}$ semester of 2010 at the faculty of management in a private university in Malaysia. The university has been in existence for more than ten years. A structured questionnaire was used in the survey. The respondents (students) were asked to respond on questions covering lecture facilities, ancillary facilities, facilitating process, explicit and implicit services and end up with demographic information. A survey was distributed randomly to 500 students out of which about 200 were returned and completed by the respondents.

\section{FINDINGS}

The overall findings extracted from the survey are summarized in Figures 1-5 categorized under Teaching Facilities, Support Facilities, Facilitation, Explicit Services, and Implicit services. Figure 1 shows that $72 \%$ of the respondents acknowledge the importance of having good teaching facilities (lecture and tutorial room, appropriate class sizes and well supported with teaching and learning equipment) but a lesser percentage are not satisfied with the provision of such facilities.

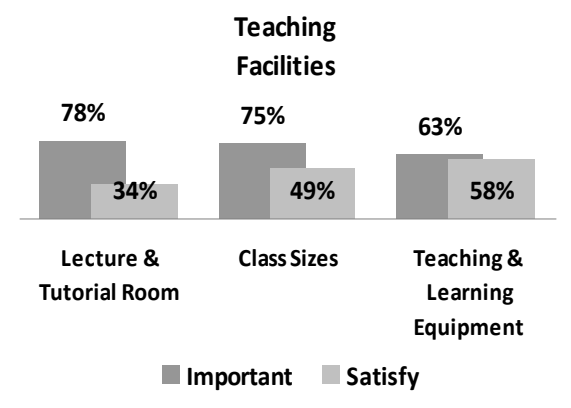

Fig. 1. Teaching facilities

Of the respondents surveyed, $80 \%$ agreed the importance of support facilities comprising of adequate learning resource center, IT and accommodation facilities. However, there is a wide gap existing with the provision of such facilities, especially accommodation.

Similar results were obtained for Facilitation although the gap seems to be narrower. $79 \%$ of students believe that the lectures and materials provided should be at the highest levels. They see the importance of these factors and do agreed the imposing of tuition fees (78\%) to comprehend the services rendered 


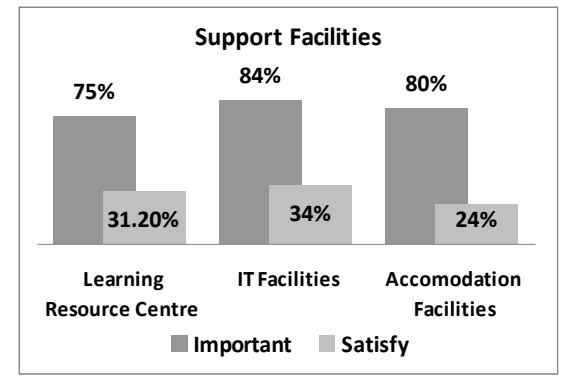

Fig. 2. Support Facilities

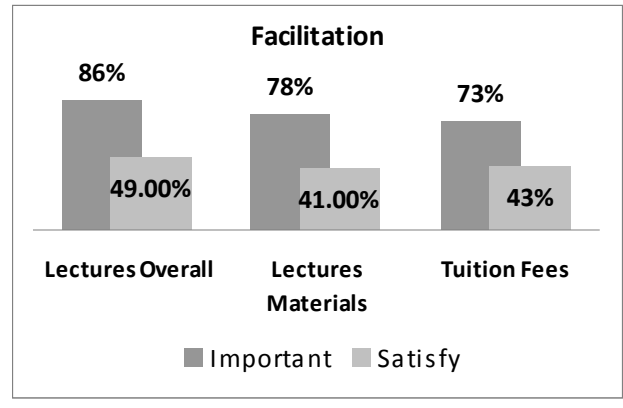

Fig.3. Facilitation

With respect to the teaching facilities and the tangible support, they (the students) want the lecturers to have the expertise and the ability to deliver the teaching with consistent teaching quality and constant feedbacks to be given to students.

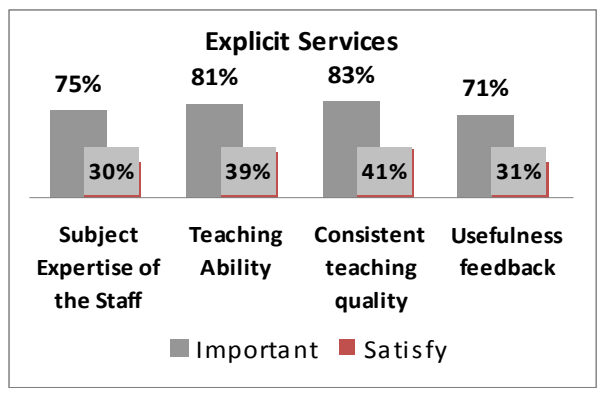

Fig. 4. Explicit Services

Finally, they also see the importance of implicit factors at $77 \%$ such as friendliness of teaching staff with an approachable attitude. Having said all the factors directly influence the quality of learning, the importance of ambience contributed from good university environment which comprehend good management.

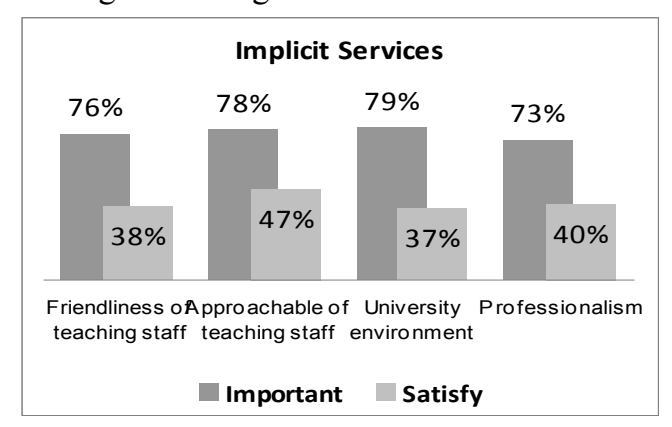

Fig.5. Implicit Services

Overall, indicators of the satisfactory level reveal a different story. The satisfaction level of all the indicators conveys that there is a gap that needs improvement by the university management. On the teaching facilities, the means shows a satisfaction level of $47 \%$, while the support facilities were $30 \%$. The lectures, lectures materials and tuition fees are rated by students at $44 \%$ satisfactory. Explicit services which deal with staff subject knowledge, teaching ability, consistent quality and feedback to student was not high, the satisfaction level were 35\%. Friendliness of teaching staff, approachability, the university environment and professionalism fare at $41 \%$ level of satisfaction. In contrast to the importance of each respective variable of the related teaching indicators, there is a need for the university management to improve the student's satisfaction levels to $70 \%$. Under the rule of thumb, the higher the percentage the better it is as it reflects a good indicator which signifies students' satisfaction in this context.

\section{Discussions AND CONCLUSION}

Based on the simple analysis of the survey findings using basic percentage measurement shows that there is need to practice effective teaching management which can satisfy students' expectations. Many do agree that students, which include undergraduates themselves, are part of an investment that could bring about changes and return to many stakeholders. In establishing an identity of educational excellence, investment in human capital has always been accepted as a source of stability and competitive advantage. Thus, there should be consistency in the support by encouraging line management in individual schools and facilities to develop staff at all levels to meet the broad goals, the divisional objectives and individual maximum potential [18]. Quality can only be embedded successfully in a department or a university when there is a high-level management and leadership abilities [19]. This justifies the view that higher education is in actual fact a business-like enterprise, where the student as a consumer seeks a business-like relationship with the producer (lecturer) that delivers knowledge, skills and competencies he or she wants [20]. [21]Today, school environment, teachers' qualifications, curriculum and instructional approaches, and many other factors interact to produce growth in students' academic skills and knowledge [22]. Central to quality teaching is not just the ability of lecturers or educators to deliver lessons effectively and competently but also conducive physical environment, good and up to date facilities which reflect good and efficient teaching management.

Conducive physical environment demand good and up to date facilities such as more smart classroom which add to lecturer convenient and readiness to teach with the usage of the latest technology. Space to move around, chairs and tables for the comfort of students to absorb lesson may sound unimportant but there are proof that hard surface chairs or impractical table causes students to be restless and lose attention. On the area of technology, the use of online resources should be widen and forcedly encourage on student. Not just to upload notes, but widen the scope into many functions, this culture should be inculcated to both students as well as lecturers.

Good management which created conducive learning and teaching is not merely the concentration of offering nice 
written program having partnership with foreign universities in the form of franchised, astounding college with concrete buildings or lauded with large intake of students. These are quantitative assessment which does not guaranteed success towards output of quality students of self reliance, independence and sense of intellectuality. The successful business school or universities of the future will need to ensure an adequate level of resources to concretize their mission statements and afford qualified faculty, will need adequately funded doctoral research programmes in this field, will need to globalise their faculty and student body but also their curricula (which will have to be reshaped to be both multi-cultural and multi-disciplinary), and will train students to become globally responsible leaders [23]. These views underscore the need for higher learning institutions without hesitation to adopt structures which takes into consideration good teaching management leading towards conducive learning that are responsive and flexible, as both educators and students have to succeed in a competitive environment.

\section{REFERENCES}

[1] Rassiah, P, Seng YC, \& Jayabalan, J (2008), The relationship between student satisfaction and academic performance in the private highe education institutions in Malaysia, $8^{\text {th }}$ Annual SEAAIR Conference, 4-6 November, Surabaya, Indonesia.

[2] Cornuel, E, (2007), Challenges facing business schools in the future, Journal of Management Development, Vol. 26 No 1.

[3] Kelly, L (2002), What is learning ... and why do museums need to do something about it? Paper presented at Why Learning? Seminar Australian Museum/University of Technology Sydney, 22nd November

[4] Amaratunga, D \& Baldry, D (2000).Assessment of facilities management performance in higher education properties, Facilities, Volume 18 . Number 7/8 . 2000 .pp. 293-301

[5] Lomas, L. (2004), Embedding quality: the challenges for higher education, Quality Assurance in Education, Vol. 12, No. 4, p.p. 157-165.

[6] Gordon, G. (1999), Managing the changes inherent in developing the Learning Society: issues, choices and strategies, Quality Assurance in Education, Vol 7. Number 3 1999. pp. 141-148

[7] Lopez, I.G, (2006), Dimensions for evaluating university quality in the European Space for Higher Education, Electronic Journal of research in Educational Psychology, No. 10, Vol. 4 (3), pp 445-468.

[8] Ashraf, M.A, Ibrahim, Y \& Joarder, M.H.R. (2009), Quality Education Management at Private Universities in Bangladesh: An Exploratory Study Jurnal Pendidik dan Pendidikan, Vol 24, pp17-32.

[9] Go vender, D, (1997) Appropriate theme: Overcoming Barriers to access \& success, Creating an environment conducive to adult distance learning, Personnel Practitioner: Training \&Development (SA Board for Personnel Practice), South Africa

[10] Rivera-Camino, J. and Mejia, L. G. (2006). Management education in Ibero-America: An exploratory analysis and perspective, Journal of World Business, 41, pp 205-220.

[11] Findley, B and Varble, D. (2006). Creating a Conducive Classroom Environment: Classroom Management Is the Key, College Teaching Methods \& Styles Journal - Third QuarterVol. 2, No. 3

[12] Srikanthan, G and Dalrymple, JF (2007), A conceptual overview of a holistic model for quality in higher education, International Journal of Educational Management Vol. 21 No. 3
[13] Kwa, Sk, (2007), Medical Education Notes for the Primary Care Teachers, How do adults learn?, Malaysian Family Physician

[14] Govender, D, (1997) Appropriate theme: Overcoming Barriers to access \& success, Creating an environment conducive to adult distance learning, Personnel Practitioner: Training \&Development (SA Board for Personnel Practice), South Africa

[15] Ibid.

[16] Ibid

[17] Dart, J (2006 ) Developing a Learning Environment Conducive to Active Learning and Participation: Group Presentations and Formative Assessment at Level One, Journal of Hospitality, Leisure, Sport and Tourism Education,

[18] Quayle, M and Murphy, J. (1999), Investors in People in further and higher education: the critical issues, Quality Assurance in Education, Volume 7. Number 4. pp. $181-189$

[19] Lomas, L. 2004, Embedding quality: the challenges for higher education, Quality Assurance in Education, Vol. 12, No. 4, p.p. 157-165.

[20] Newton, J. (2006). What is quality? $1^{\text {st }}$ European Forum for Quality Assurance, Nov 2006: 14-2

[21] Chepchieng M.C, Mbugua, S.N. and Kariuki, M.W. (2006), University students' perception of lecturer-student relationships: a comparative study of Public and Private Universities in Kenya, Educational Research and Reviews, Vol. 1 (3), pp. 80-84, June 2006

[22] Ud-Din, Kamal Khan and Mahmood, (2010), Effect of Teachers' Academic Qualification on Students' L2 Performance at the Secondary Level, Language in India, Vol. 10

[23] Cornuel, E, (2007), Challenges facing business schools in the future, Journal of Management Development, Vol. 26 No 1.

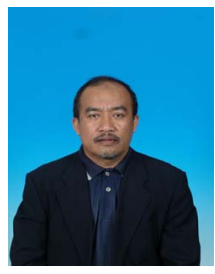

Sabarudin Zakaria, was born in Kuala Pilah Malaysia on the $6^{\text {th }}$ February 1956 . He attends King George V Secondary school from 1968 to 1973 and later study at University Science Malaysia where he obtained his Bachelor in Social Science (Hons). Author then completed his MBA in 1997 from the University of Liverpool, United Kingdom specialized in Industrial Development. The author became a member of Institute of Training and Development (UK) when he obtained his Diploma in Training Management.

Then he began his career as a credit officer in a local bank in 1982. For the first five years he had experienced in dealing with customers from various backgrounds dealing in various banking transaction especially financing. With the experienced on the field he later joined the training department and spends for the next 13 years as full-time trainer in the area of financing. He spends a total of twenty years in the banking industry. He later joined Multimedia University, Cyberjaya, Malaysia in 2008 as a lecturer specialized in teaching management subject. His areas of research are teaching and learning, islamic finance and corporate social responsibility. To date he has written and published several articles in journals and conferences.

Mr. Sabarudin has been appointed as the associate editor by Journal of Social Science to review papers for publication and conferences. University National of Malaysia(UKM) has also nominated Mr. Sabarudin as the technical reviewer to review paper for their national conferences on economics.

Wan Fadzilah Wan Yusoff, is the Associate Professor for the Faculty of Management, Multimedia University, Malaysia. Her areas of research interests are in intellectual; capital, knowledge management, performance management and strategy. Prior to joining the academia, she has accumulated 18 years of industry experience in banking and financial sector. 